\title{
Thermal Evaporation of Amorphous Chalcogenide on Single-mode Optical Fiber
}

\author{
Sung-Tae Hwang, Kyuman Cho, Bonghoon Kang*, and Gi-Tae Joo**广 \\ Department of Physics, Sogang University, Seoul 121-742, Korea \\ *Department of Visual Optics, Far East University, Chungbuk 369-700, Korea \\ **Materials Science \& Technology Research Division, Korea Institute of Science and Technology, Seoul 136-791, Korea \\ (Received December 4, 2009; Revised December 16, 2009; Accepted December 21, 2009)
}

\section{단일 모드 광섬유 표면의 비정질 Chalcogenide 열 증착 \\ 황성태 - 조규만 - 강봉훈* - 주기태*** \\ 서강대학교 물리학과 \\ *극동대학교 안경광학과 \\ **한국과학기술연구원 재료기술연구본부 \\ (2009년 12월 4일 접수 ; 2009년 12월 16일 수정 ; 2009년 12월 21일 승인)}

\begin{abstract}
We made a film of a few $\mu \mathrm{m}$ thickness by evaporating $\mathrm{As}_{2} \mathrm{~S}_{3}$ piece to perpendicularly cut optical fiber by thermal evaporation process. Linear refractive index(n) and linear absorption coefficient $(\mathrm{k})$ of amorphous $\mathrm{As}_{2} \mathrm{~S}_{3}$ are 2.525 and $1.727 \times 10^{-3}$, respectively. A surface roughness did not exceed $2 \mathrm{~nm}$ and a transmission spectrum showed that the sample of thermal evaporation was homogeneous.
\end{abstract}

Key words : Single-mode optical fiber, Amorphous chalcogenide, $A s_{2} S_{3}$, Thermal evaporation

\section{1. 서 론}

비정질 매질인 칼코게나이드 유리는 다양한 광유도 현 상을 보이며 이러한 광학적 현상은 비선형 굴절률이나 흡 수계수 등과 같은 비선형 광학상수에 의해 설명된다. 비정 질 칼코게나이드 유리에 띠 간격(band-gab) 또는 서브 띠 간격(sub-band-gab)의 빛을 광조사(illumination)하면 optical Kerr effect에 의한 자체집광(self-focusing) ${ }^{1,2}$ 현상이 나타난 다. 그리고 광유도 구조변화(photoinduced structure change) 에 의한 광팽창(photoexpansion) ${ }^{3-5)}$ 및 광수축(radiation contraction) 등의 부피변화 현상ㅇㄱㄱㅘ 광조사에 따른 굴절률 변 화 ${ }^{710)}$ 현상인 광암색화(photodarkening) ${ }^{11)}$ 현상 등이 나타 난다. 이러한 다양한 현상들 중에서 Optical Kerr effect에 기인하는 자체집광(Self-focusing)현상은 매우 높은 집적도 를 가지는 광기록매체의 제작에 응용 가능하기 때문에 많 은 연구자들에 의해 광범위하게 연구되어왔다. ${ }^{12)}$

$\mathrm{As}_{2} \mathrm{~S}_{3}$ 는 단사정 층상구조(monoclinic layer structure)를 이루고 있으며 각각의 $\mathrm{As}$ 원자들은 3 개의 $\mathrm{S}$ 원자들과 결합 하여 밑면이 3 개의 $\mathrm{S}$ 원들로 구성되고 정점은 하나의 $\mathrm{As}$

\footnotetext{
${ }^{\dagger}$ Corresponding author : Gi-Tae Joo

E-mail : jgt1580@kist.re.kr

Tel : +82-2-958-5515 Fax : +82-2-958-5489
}

원자로 구성되어 있는 편편한 피라미드 형태의 배열을 하 고 있다. 또한 각각의 $\mathrm{S}$ 원자들은 2 개의 피라미드의 각 한 부분을 이루고 있으므로 모든 $\mathrm{As}$ 원자와 $\mathrm{S}$ 원자들은 서로 공유결합을 하고 있으며 모든 공유결합 물질과 마찬가지 로 각각의 원자들은 Van der Waals 힘으로 연결되어 있 다. Band gap 에너지는 약 $2.4 \mathrm{eV}$ 정도이지만 비정질 반 도체의 특성상 band edge가 정확하게 결정되지 않기 때 문에 tail absorption이 있다. 즉, band gap 에너지 보다 적 은 에너지를 갖는 빛의 흡수가 일어나는데 흡수계수의 크 기가 $h \mathrm{v}-\mathrm{E}_{\mathrm{g}}$ 에 지수 함수적으로 비례한다. 칼코게나이드 비정질 반도체가 band tail에서 매우 큰 3차 비선형계수를 갖는 이유는 아직 정확하게 밝혀지지 않았으나, 작지만 band tail에서 흡수가 일어나기 때문에 이 과정에서 발생 하는 self-trapped exciton에 의한 효과가 가장 큰 영향을 미 친다. 따라서 band tail에서 벗어날수록 3차 비선형 계수 의 크기가 작아지고, 또한 광 유도 현상들도 작아지게 된 다. 따라서 입사 빛의 파장에 따라 광 유도 현상 및 자체 집광효과를 복합적으로 관찰함으로써 칼코게나이드 반도 체에서 일어나는 여러 가지 현상들에 대한 정량적인 연 구를 수행할 수 있다. 반도체 레이저의 경우 $\mathrm{As}_{2} \mathrm{~S}_{3}$ 의 band tail의 전 영역 및 이보다 훨씬 긴 파장까지 거의 연속적 으로 광원을 구할 수 있기 때문에 광 유도 현상, $\mathrm{SF}$ 현상 


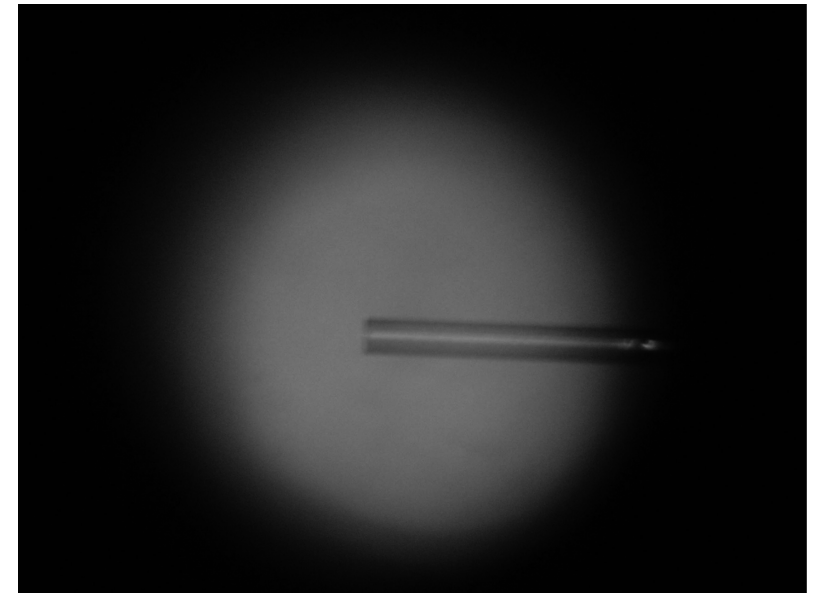

Fig. 1. Photograph of cleaved single-mode optical fiber.(before thermal evaporation)

을 비롯하여 여러 가지 선형 비선형 광학적 특성을 측정 할 수 있다.

본 연구에서는 단일모드 광섬유 단면 위에 비정질 chalcogenide $\mathrm{As}_{2} \mathrm{~S}_{3}$ 를 열증착 방법을 사용하여 증착하였으 며, 광섬유의 증착 표면 및 증착된 $\mathrm{As}_{2} \mathrm{~S}_{3}$ 의 광투과도, 굴 절률 및 선형 흡수계수 등을 살펴보았다.

\section{2. 실험 방법}

Fig. 1은 수직 절단된 광파이버의 광학 현미경사진이다. 본 실험에서 기판으로서 사용된 광섬유는 단일모드 광섬 유(3M Model FS-SN-3224)로서 그 사양은 다음과 같다. 광섬유에 대한 작동파장은(operating wavelength) $630 \mathrm{~nm}$ 이며 Mode Field Diameter는 $4.0 \mu \mathrm{m}$ 이고 cladding은 $125 \mu \mathrm{m}$ 이고 NA는 0.12 이다.

이 광섬유에 $\mathrm{As}_{2} \mathrm{~S}_{3}$ 를 증착하고 레이저 빛살을 광섬유에 넣어줌으로써 원형의 평행광이 샘플에 입사하는 것으로 간주할 수 있다. 이와 같은 광섬유에서 재킷(jacket)을 벗 긴 후 광섬유 절단기(fiber cleaver)로 광섬유를 수직 절단 하고 여기에 $\mathrm{As}_{2} \mathrm{~S}_{3}$ 샘플을 증착하였다. 이때, 증착은 열 증 착법(thermal evaporation)을 이용하였다. $\mathrm{As}_{2} \mathrm{~S}_{3}$ 조각은 모 래알 크기로 잘게 부셔서 사용하였으며 텅스텐 boat를 이 용하는 경우에는 boat와 $\mathrm{As}_{2} \mathrm{~S}_{3}$ 가 서로 화학반응을 일으켜 순수한 $\mathrm{As}_{2} \mathrm{~S}_{3}$ 박막을 얻을 수 없기 때문에 quartz crucible 에 넣어 가열하였다. 증착 시 진공도는 $~ 5 \times 10^{-6}$ Torr이었

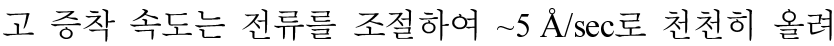
증착속도가 빠르거나 변동이 심할 때 발생하는 균열을 최 대한 적게 하였다. 또한 샘플이 증착된 후 vent 전에 진공 상태에서 1 시간 이상 냉각시간을 두었다.

증착된 샘플에 대한 두께 측정은 진공장비에 장착되어 진 thickness monitor로 측정하였으며 좀 더 정확한 값을

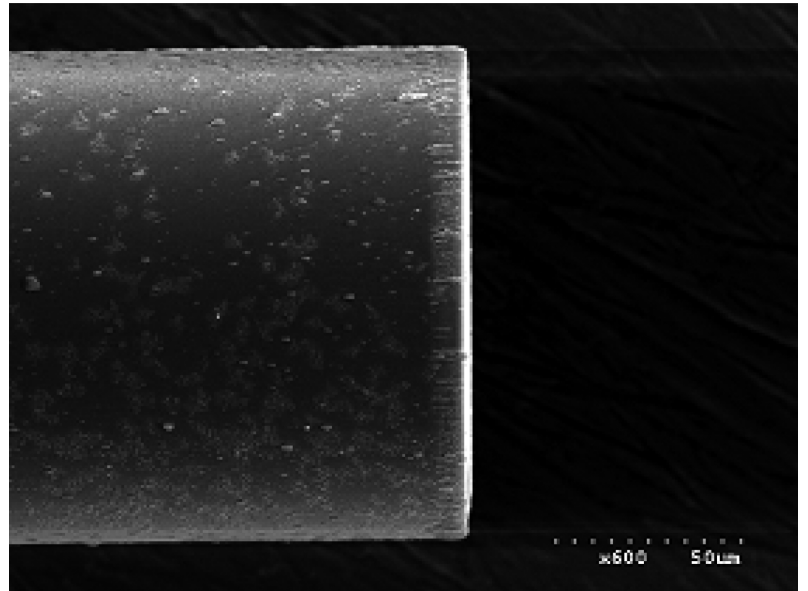

Fig. 2. SEM image of thermal evaporated optical fiber.

알기 위하여 미리 넣어둔 슬라이드 글라스에서 증착된 일 부를 벗겨내고 stylus ( $\alpha$-step 200, Tenco Co.)를 이용하여 재차 측정하였다. 광 투과도 측정은 Spectrophotometer(UV$4100, \mathrm{HITACHI}$ 를 사용하여 측정하였으며, Commercial spectroscopic ellipsometer (J. A. Wollan, VASE)를 사용 하여 원하는 파장에 대한 굴절률을 측정하였다.

\section{3. 결과 및 고찰}

Fig. 2는 수직 절단된 fiber 단면에 열 증착 된 $\mathrm{As}_{2} \mathrm{~S}_{3}$ 박 막의 $\mathrm{SEM}$ 이미지이다. 열 증착 공정을 통하여 $1.6 \mu \mathrm{m}$,

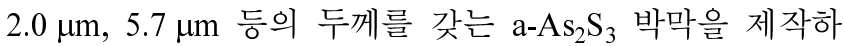
였으며, commercial spectroscopic ellipsometer (J. A. Wollan, VASE)의 측정결과로부터 $633 \mathrm{~nm}$ 의 $\mathrm{He}-\mathrm{Ne}$ 레이저 파장대 에 대해서 선형 굴절률 $(\mathrm{n})$ 은 2.525 이고 선형 흡수 계수 $(\mathrm{k})$ 는 $1.727 \times 10^{-3}$ 이라는 것을 알 수 있었다.

Fig. 2에서와 같이 광섬유에 샘플을 증착하면 샘플에 입 사되는 빛살이 광섬유를 통과하여 입사하므로 대칭을 가 지고 있는 이상적인 빛살을 만들 수 있다. 또한 기하광학 계와는 다르게 광학적인 정렬이 불필요 하게 된다. 샘플 은 정확히 입사되는 빛살에 대해 수직으로 놓이게 되며 광섬유의 mode field diameter(MFD)가 정해져 있으므로 샘플에 입사되는 빛살의 크기가 일정하다고 볼 수 있다. 따라서 반도체 레이저와 같은 비대칭적인 빛살도 광섬유 에 의해 대칭적인 빛살로 만들 수 있으므로 광원의 형태 에 영향을 받지 않는다. 또한, 광조사에 사용되는 빛살을 공간잡음(spatial noise)이 없는 이상적인 빛살로 만들기 위 한 추가적인 장비가 필요 없다. 또한 슬라이드 글라스에 서의 다중반사(multiple reflection)된 빛에 의해서 자체집 광이 영향을 받을 수 있기 때문에 정량적인 측정에 어려 움이 있다. 다음으로 슬라이드 글라스에 증착한 방법에 비해 열처리가 쉽다. 샘플과 유리의 열팽창 계수차이로 

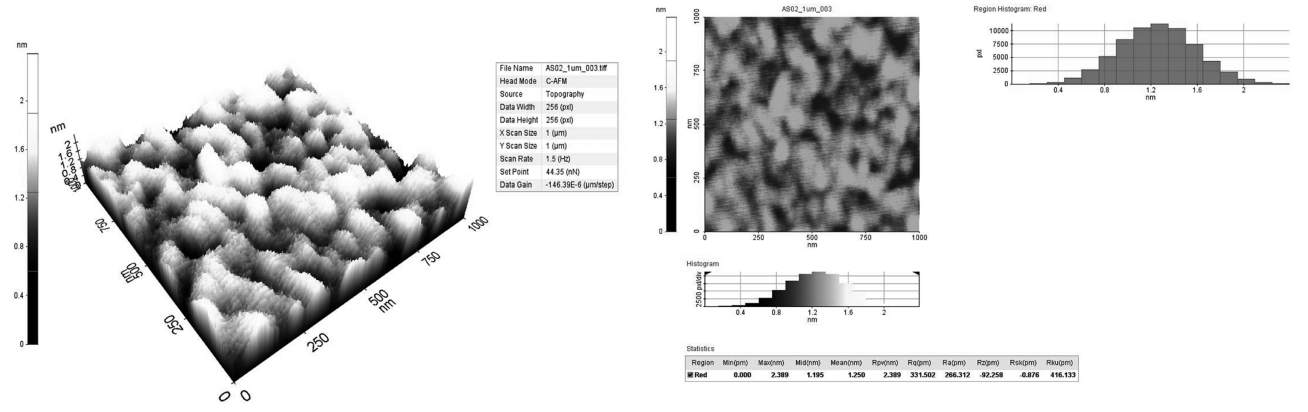

(a)

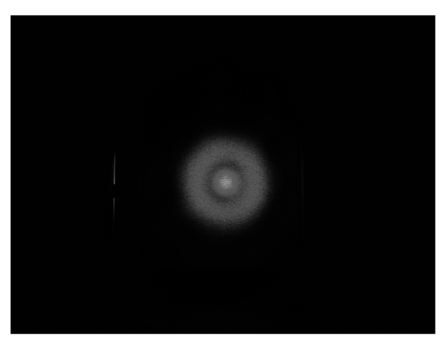

(b)

Fig. 3. (a) AFM image of sample after thermal evaporation $(1 \mu \mathrm{m} \times 1 \mu \mathrm{m})$. RMS roughness is $0.33 \mathrm{~nm}$. (b) Transmitted laser beam image when linear polarized beam enters the film.

인해 열처리 시 샘플이 깨지는 현상 등이 발생하는데 반 해 광섬유에 증착하게 되면 광섬유의 지름이 $125 \mu \mathrm{m}$ 정 도로 매우 작기 때문에 열처리가 수월하고 시간에 대하 여 거의 변화가 없는 빛살을 비선형 매질에 전달 할 수 있으며, 샘플의 이동 또한 쉬워진다.

Fig. 3(a)은 열 증착(thermal evaporation)하여 올린 샘플 의 표면 거칠기에 대한 $\mathrm{AFM}$ 이미지이다. 표면영역은 $1 \mu \mathrm{m} \times 1 \mu \mathrm{m}$ 이며 표면의 거칠기는 $2 \mathrm{~nm}$ 를 넘지 않았다. Fig. 3(b)에서는 수직 절단된 fiber에 균일하게 열증착된 $\mathrm{As}_{2} \mathrm{~S}_{3}$ film을 통과하는 laser 빛살에 대한 이미지를 보였 다. 일반 기하광학계와는 달리 공간 잡음이 없는 이상적 인 빛살을 만들 수 있었으며, 다중 반사 등을 고려하지 않는 광-물질간의 상호작용을 규명하기 위한 이상적인 상 황이 구현 되었다. 현재 진행 중인 자체집광현상이나 필 라멘테이션 그리고 다양한 광유도 현상 등을 실험적으로 밝히기 위해서는 우선 회절한계를 넘어선 분해능으로 이 를 관찰할 수 있어야 한다. 이와 같은 연구의 목적에 맞 게 실험장치 및 방법을 획기적으로 개선하여 다양한 광 유도 현상에 대한 정량적인 분석을 시도하고 있다.

Fig. 4에서는 글라스 및 박막이 있는 글라스에 대한 흡 수 스펙트럼이다. 박막은 다중반사에 의한 간섭효과로 흡 수 스펙트럼은 파장에 따라서 주기적으로 극대와 극소 값 을 가짐을 알 수 있다. Fig. 4(a)는 기판으로 사용한 글라 스의 투과율을 나타내고 Fig. 4(b)는 고르게 증착된 샘플

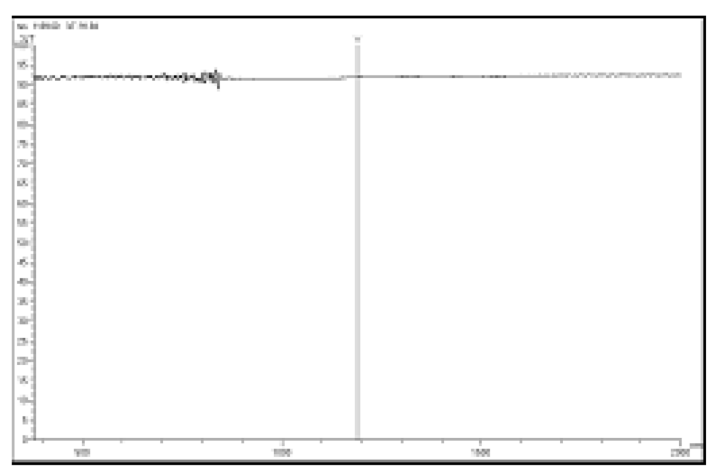

(a)

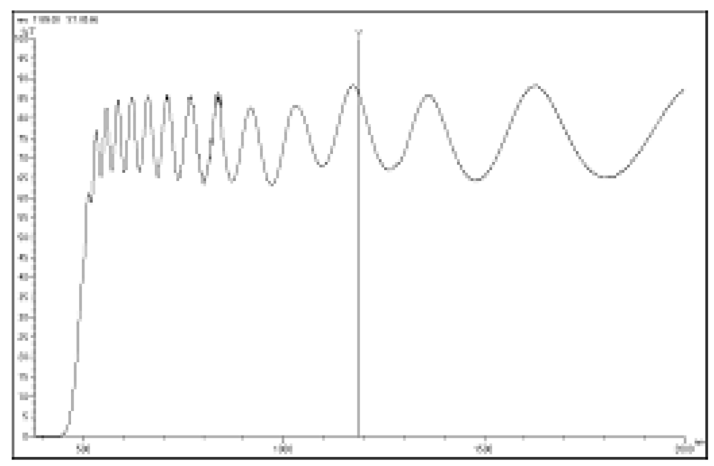

(b)

Fig. 4. Transmission spectrum of substrate(slide glass)(a) and thermal evaporated amorphous $A s_{2} S_{3}$ thin film.(b) 
의 투과율이다. $400 ~ 530 \mathrm{~nm}$ 부근에서는 비정질 $\mathrm{As}_{2} \mathrm{~S}_{3}$ 의 흡수영역 끝(absorption edge) 부근이므로 강한 흡수영역 을 가져 내부의 간섭효과가 무시되고, $570 \mathrm{~nm}$ 이상의 영 역 에서는 투과율의 극대값이 기판의 투과율(0.9)과 거의 같다. 가시광선 영역에서 보면 기판의 투과율은 거의 일 정하다. 또한 투과율의 스펙트럼에서 박막 두께가 균일하 지 않다면 박막 내부에서 다중간섭 효과는 크게 감소하 거나 없어질 것이므로 Fig. 4(b)와 같이 주기적으로 진동 하는 그림을 얻을 수 없다.

\section{4. 결 론}

수직 절단된 단일모드 광섬유 단면에 비선형광학 매질 $\mathrm{As}_{2} \mathrm{~S}_{3}$ 를 열 증착법으로 균일 두께의 박막을 증착하였다. 위와 같이 광섬유 단면에 직접 증착하여 빛이 다른 매질 을 진행하지 않고 직접 시료에 조사됨으로서, 이는 일반 기하광학계와는 달리 공간 잡음이 없는 이상적인 빛살을 만들 수 있는 조건이며, 다중 반사 등의 외부 영향이 없는 광-물질간의 광유도 현상 등을 직접적으로 규명하기 위한 이상적인 상황을 구현할 수 있는 조건이라 할 수 있다.

열 증착 공정을 통하여 $1.6 \mu \mathrm{m}, 2.0 \mu \mathrm{m}, 5.7 \mu \mathrm{m}$ 등의 두 께를 갖는 $\mathrm{a}_{-} \mathrm{As}_{2} \mathrm{~S}_{3}$ 박막을 제작하였으며, $633 \mathrm{~nm}$ 의 $\mathrm{He}-\mathrm{Ne}$ 레이저 파장대에 대한 선형 굴절률(n)은 2.525 이고 선형 흡수 계수 $(\mathrm{k})$ 는 $1.727 \times 10^{-3}$ 로 측정되었다. 증착된 시료의 표면 거칠기는 $2 \mathrm{~nm}$ 를 넘지 않는 균일한 박막이 형성되 었음을 확인 할 수 있었으며, 투과 스펙트럼으로부터 박 막 두께가 균일할 때 보이는 다중반사의 스펙트럼을 확 인할 수 있었다.

\section{Acknowledgment}

본 연구는 한국과학기술연구원(KIST) 기관고유사업의 지원으로 이루어졌습니다.

\section{RERERENCES}

1. P. L. Kelley, "Self-Focusing of Optical Beams," Phys. Rev. Lett., 15 1005-8 (1965).

2. R. Y. Chiao, E. Garmire, and C. H. Townes, "Self-Trapping of Optical Beams," Phys. Rev. Lett., 13 479-82 (1964).

3. K. Tanaka, "Electron Beam Induced Reliefs in Chalcogenide Glasses," Appl. Phys. Lett., 70 261-63 (1997).

4. H. Hisakuni and K. Tanaka, "Optical Fabrication of Microlenses in Chalcogenide Glasses," Opt. Lett., 20 958-60 (1995).

5. H. Hisakuni and K. Tanaka, "Giant Photoexpansion in $\mathrm{As}_{2} \mathrm{~S}_{3}$ Glass,” Appl. Phys. Lett., 65 2925-27 (1994).

6. K. B. Song, J, K. Lee, J. H. Kim, and K. Cho, "Direct Observation of Self-Focusing with Subdiffraction Limited Resolution Using Near-Field Scanning Optical Microscope," Phys. Rev. Lett., 85 3842-45 (2000).

7. T. Gotoh and K. Tanaka, "Photoinduced Surface Deformations in Ion-conducting Ag-As-S Glasses. II. Anisotropic Deformation Produced by Large Light Spots," $J$. Appl. Phys., 89 4703-6 (2001).

8. K. Tanaka, "Photoinduced Deformations in Chalcogenide Glasses: Scalar and Vectoral," J. Opotoelectronics and Advanced Materials., 7 2571-80 (2005).

9. K. Tanaka and Hideaki Asao, "Photoinduced Anisotropic Deformation in $\mathrm{As}_{2} \mathrm{~S}_{3}$ Glass," Jpn. J. Appl. Phys., 45 1668-74 (2006).

10. H. Asap and K. Tanaka, "Polarization-dependent Photoinduced Mechanical Deformations in Covalent Chalcogenide Glasses," J. App. Phys., 102 043508-14 (2007).

11. S. Ramachandran, S. G. Bishop, J. P. Guo, and D. J. Brady, "Fabrication of Holographic GRatings In $\mathrm{As}_{2} \mathrm{~s}_{3}$ Glass By Photoexpansion And photodarkening," IEEE Photo. Tech. Lett., 8 1041-43 (1996).

12. E. Garmire, R. Y. Chiao, and C. H. Townes, "Dynamics and Characteristics of the Self-Trapping of Intense Light Beams," Phys. Rev. Lett., $16347-9$ (1966). 